\title{
Coulisses
}

Revue de théâtre

15 | Hiver 1997

Varia

\section{Le Festival des Nuits de Joux}

\section{Pierre Louis}

\section{OpenEdition}

Journals

Édition électronique

URL : http://journals.openedition.org/coulisses/5026

DOI : $10.4000 /$ coulisses. 5026

ISSN : 2546-9460

\section{Éditeur}

Presses universitaires de Franche-Comté

\section{Édition imprimée}

Date de publication : 1 janvier 1997

Pagination : 25

ISSN : 1150-594X

\section{Référence électronique}

Pierre Louis, «Le Festival des Nuits de Joux », Coulisses [En ligne], 15 | Hiver 1997, mis en ligne le 26 avril 2019, consulté le 23 octobre 2019. URL : http://journals.openedition.org/coulisses/5026 ; DOI 10.4000/coulisses.5026

Ce document a été généré automatiquement le 23 octobre 2019

Coulisses 


\title{
Le Festival des Nuits de Joux
}

\author{
Pierre Louis
}

1 Le festival des Nuits de Joux 96 a affirmé sa vocation de manifestation ouverte à la création, propice à la recherche scénographique, apte à accueillir les meilleurs spectacles du moment et bien placée pour tisser les liens avec artistes et spectateurs suisses romands.

Chaque année, pour sortir des sentiers battus le festival essaie de se renouveler, de tenter des expériences. Il ne s'agit pas de dérouter un public caractérisé par sa fidélité (il $\mathrm{y}$ a des spectateurs qui suivent les spectacles du festival, et en particulier les comédiens des Nuits de Joux, depuis une bonne dizaine d'années) et par son attachement à la magie d'un lieu et d'un soir - opération délicate, mais il suffit de réserver à ce public des surprises et des innovations compatibles avec le cadre et la saison du festival.

En 1996 c'est le cinéma qui a fait son entrée au Château de Joux, à l'initiative de la Région de Franche-Comté avec les soirées "Cinéma pour ciel d'été ", projection de deux films grand public sur écran géant, au milieu des installations scéniques. Pour Les Misérables de Lelouch, la cour d'honneur du château avec 579 spectateurs fut probablement la salle la plus remplie de tous les cinémas de la région, avec en prime les étoiles dans le ciel. Autre innovation, l'investissement d'un lieu inusité dans l'enceinte du château pour la création du spectacle des Comédiens des Nuits de Joux Une petite gare en France. Création originale à double titre donc: texte original de Pierre Louis, utilisation d'un décor naturel. Spectacle en deux parties, relatant des faits survenus à deux époques, avril 45 et août 45, et abordant des thèmes que le théâtre en France n'a guère l'habitude de traiter: A quels problèmes au juste les Français ont-ils été confrontés au moment de la libération? Que fallait-il faire de Vichy? Et aujourd'hui quel regard peut-on porter sur les hommes et les événements de cette tragédie sans véritable dénouement qu'a été la guerre et l'occupation, la collaboration et la résistance?

Devoir de mémoire, si nécessaire et auquel le théâtre, en référence à ses origines mêmes se doit de contribuer. Alfred Simon disait: «Le théâtre est notre possible de gloire ». Et si le théâtre était notre possible de mémoire ? Une petite gare en France a été jouée 7 fois, touchant 753 spectateurs, ce qui représente un succès compte tenu des 
mauvaises conditions atmosphériques, du sujet, et du genre. Plusieurs metteurs en scènes amis et directeurs de théâtre sont venus saluer la performance...

2 Encadrant cette création, les spectacles invités ont séduit les publics les plus variés. L'absinthe a été l'occasion de découvrir une artiste qui a donné ses lettres de noblesse au cabaret chanté : Hélène Delavault qui, seulement accompagnée d'un piano, a tenu la scène à ciel ouvert de la cour d'honneur du Château de Joux. Marcel Bozonet est venu avec son spectacle La Princesse de Clèves pour tenter lui aussi l'expérience du plein air. Enfin deux jeunes compagnies vinrent faire leurs armes à leur tour: Le Théâtre du Voyageur dans une cour d'école au centre ville de Morteau, l'Helvetic Shakespeare Company dans la cour du Château de Joux. Plaisir de la découverte: Celle de Karl Valentin et du traitement musical, chorégraphique, clownesque en diable d'une troupe de douze acteurs rompus à un genre difficile, celui d'une lecture originale, mais peutêtre trop fragmentaire, d'une grande pièce de Shakespeare.

3 De quoi s'interroger sur les cheminements de la création de part et d'autre de la frontière. Et remplir sa besace aux souvenirs le temps d'un été. C'est en cela que le Festival des Nuits de Joux s'avère peut-être bien irremplaçable, s'adressant à la fois aux amateurs éclairés, aux habitants du Haut-Doubs qui ne vont au théâtre qu'à l'occasion, et aux touristes qui apprécient l'animation du patrimoine qui leur est ainsi proposée. 